\title{
Qualidade e relevância da produção científica nas ciências da saúde: práticas de citação na área de pneumologia. Parte II
}

\section{Quality and relevance of the scientific production in the health sciences: citation practices in the area of pneumology. Part II}

Maria de Fátima Borges Gonçalves

ORCID: https://orcid.org/0000-0003-3175-7105

Doutoranda pelo Programa de Pós-Graduação em Clínica Médica da Universidade Federal do Rio de Janeiro (UFRJ) Professora do Departamento de Biblioteconomia da Universidade Federal do Rio de Janeiro (UFRJ) goncalves57@yahoo.com.br
Vania Lisboa da Silveira Guedes ORCID: https://orcid.org/0000-0001-5854-5677 Doutora em Linguística pelo Programa de Pós-Graduação em Linguística da Universidade Federal do Rio de Janeiro (UFRJ)

Professora do Departamento de Biblioteconomia da Universidade Federal do Rio de Janeiro (UFRJ) guedesvania@yahoo.com.br

José Roberto Lapa e Silva

ORCID: https://orcid.org/0000-0003-3116-0253

Doutor em Imunopatologia Pulmonar - National Heart and Lung Institute. Imperial College London

Professor do Departamento de Clínica Médica da

Universidade Federal do Rio de Janeiro (UFRJ)

jrlapa@hotmail.com 
RESUMO: $\bigcirc$ presente artigo revela os resultados finais da pesquisa de doutorado em Clínica Médica da Universidade Federal do Rio de Janeiro com o mesmo título. Pesquisadores, através

1Pesquisa de doutorado do Programa de Pós-Graduação em Clínica Médica. Faculdade de Medicina da Universidade Federal do Rio de Janeiro - UFRJ. de sua produção científica são constantemente avaliados no que diz respeito à qualidade e à relevância do seu trabalho e a contagem de citação revela-se como uma das métricas mais frequentemente utilizadas para esse fim. A pesquisa insere-se no contexto dos estudos cientométricos e aplica a metodologia proposta por Ahmed e outros (2004), que evidencia as razões de citação a 22 artigos indicados por 12 pesquisadores da área de Pneumologia, de sua autoria, considerados por eles como os de maior qualidade e de maior relevância, através de análise de conteúdo. Foram analisados 219 artigos citantes. Os resultados revelam que 57,6\% das citações foram motivadas pela categoria A, razões históricas, prestação de homenagem aos pioneiros, trabalhos anteriores, mesma concepção do assunto; 21,5\% das citações foram motivadas pela categoria B, descrição de outro trabalho relevante, discussão de detalhes ou partes dos resultados, explicações de como a teoria deve ser usada; 11,8\% foram motivadas pela categoria C, uso específico de informação contida no artigo citado. São apresentadas também outras categorias como resultados. A pesquisa pretendeu não apenas revelar as motivações para o ato de citar, mas contribuir para o uso mais adequado da variável citação como uma das ferramentas de avaliação da pesquisa na área de Pneumologia.

PALAVRAS-CHAVE: Análise de citação. Cientometria. Pneumologia. Avaliação da Ciência.

ABSTRACT: The present article reveals the final results of the PhD research in Clinical Medicine of the Federal University of Rio de Janeiro under the same title. Researchers through their scientific production are constantly evaluated with regard to the quality and relevance of their work and the citation count proves to be one of the most frequently used metrics for this purpose. The research is part of the scientometric studies and applies the methodology proposed by Ahmed et al. (2004), which shows the reasons for citing 22 articles indicated by 12 researchers in the field of Pulmonology, which they considered as the of higher quality and of greater relevance, through content analysis. A total of 219 citing articles were analyzed. The results show that $57.6 \%$ of the citations were motivated by category A, historical reasons, pays homage to the pioneers, previous works, same conception of the subject; $21.5 \%$ of the citations were motivated by category B, description of other relevant work, discussion of details or parts of the results, explanations of how the theory should be used; $11.8 \%$ were motivated by category $C$, specific use of information contained in the cited article. Other categories are also presented as results. The research aimed not only to reveal the motivations for the act of citing, but to contribute to the more adequate use of the citation variable as one of the evaluation tools of the research in the field of Pulmonology

KEYWORDS: Citation analysis. Scientometric Studies. Pneumology. Science Assessment. 


\section{Introdução}

Ao longo das últimas décadas, a análise de citações foi sendo incorporada aos sistemas de avaliação do desempenho científico, elaborados e conduzidos por governos e instituições de diferentes países. Neste processo, as citações passam a ter atribuição de qualidade, como também de visibilidade científica. Tal mudança na concepção do conceito de citação tem sido apontada por muitos teóricos como problemática, por apresentar uma visão restrita e inadequada desta variável.

Desta forma, outra questão, que se apresenta como não definida, é a relacionada com o conceito de qualidade e relevância de trabalhos citados, quando aplicados aos estudos de citação, sendo estes termos constantemente utilizados pelos especialistas da área em suas publicações

As principais críticas aos estudos e índices de citação referem-se à cobertura inadequada das bases informacionais que, além de indexarem uma parte pequena dos periódicos científicos mundiais, têm sério viés quando se referem à cobertura dos periódicos por país de publicação e por área de conhecimento. Outra crítica é a que diz respeito ao fato das citações serem feitas por razões variadas, envolvendo aspectos eminentemente subjetivos.

Estudos como os Oppenheim, (1995; 1997); Lewison, (1988); Tijssen et al, (2001), para citar apenas alguns, demonstram que a contagem das citações tem sido utilizada para medir o impacto do trabalho dos cientistas na comunidade científica dentro da concepção de que um número maior de citações, recebido por um determinado trabalho, estaria diretamente relacionado a uma maior qualidade (VARAAN et al., 2003).

Esta relação acima mencionada não é consenso entre especialistas, uma vez que a literatura sugere que o ato de citar um determinado trabalho tem razões variadas que incluem a prestação de homenagem aos pioneiros de uma área, dar crédito a um trabalho relacionado, servir de base teórica para um tópico, corrigir ou criticar trabalhos previamente publicados, corroborar com alguma idéia ou chamar atenção para um determinado trabalho publicado previamente, que não seja tão 
conhecido como deveria. (MAC ROBERTS, 1989; MOED, 2002; WARNER, 2000). Além disso, sabe-se que a contagem de citações reduz tudo a meros números e que critérios como qualidade e influência não são, de fato, levados em consideração. (AHMED et al, 2004)

Dentro deste contexto, Banbrilla et al. (2006) apontam que um dos maiores questionamentos a respeito das citações está na identificação dos motivos que levam determinado autor a citar outros pesquisadores. Com base em Ahmed et al. (2004), que apresentam um sistema de classificação especialmente desenvolvido para analisar as razões de citação, as autoras realizaram um estudo qualitativo sobre as citações recebidas por um trabalho da Universidade Federal do Rio Grande do Sul (UFRGS). Como resultado, o estudo aponta a identificação de apenas uma categoria dentre as sete apresentadas por Ahmed et al. (2004).

Em resposta às críticas aos índices, a literatura especializada da área apresenta alguns trabalhos que sugerem a atribuição de medidas de qualidade à pesquisa científica.

Este estudo analisa práticas de citação na área de Pneumologia, nas Ciências da Saúde, com o propósito de verificar se os artigos indicados pelos pesquisadores, que fizeram parte da amostra, como os de maior qualidade e relevância, relacionam-se de alguma forma aos mais citados de sua produção.

O artigo pioneiro de Brambilla et al. (2006) inspirou o presente trabalho que tem como objetivo principal mapear as motivações que subjazem as citações recebidas por um grupo de artigos científicos na área de Pneumologia.

Como objetivos específicos pretende-se (a) identificar, junto aos pesquisadores da área de Pneumologia, os artigos mais relevantes e os de maior qualidade para a sua produção; (b) categorizar os artigos citantes (citing articles) quanto às motivações para citarem os artigos indicados, utilizando análise de conteúdo de Bardin e a metodologia proposta por Ahmed et al. (2004); (c) correlacionar os índices de citação com o tempo dedicado por pesquisadores às atividades acadêmicas; (d) investigar que tipo de atividade acadêmica influencia a produtividade de artigos e 
o número de citações; (e) verificar o nível de coerência entre artigos relevantes e de maior qualidade, indicados pelos pesquisadores, com os conceitos de relevância e de qualidade representados em critérios apontados por eles.

Desta forma, pretende-se, por um lado identificar os aspectos sociais, teóricos e metodológicos que cercam a variável citação e, por outro, contrastar o conceito de relevância e de qualidade do trabalho científico com o número e o tipo de citação recebida por ele.

\section{Fundamentação Teórica}

Esta pesquisa tem como base o estudo conduzido por Ahmed et al (2004). Os autores conduziram um estudo de citação acerca do artigo publicado por Watson e Crick, em 1953, sobre a descoberta da dupla hélice do DNA. O referido artigo foi citado, até aquela data, mais de 2000 vezes, desde 1961, sem sinal de obsolescência até então.

Os autores, através do estudo acima mencionado, desenvolveram uma metodologia para investigar as motivações das citações ao artigo publicado. Inspecionaram os artigos citantes, no sentido de avaliar as razões que levaram os autores a citá-lo. O resultado da pesquisa demonstrou que mais de 75\% das citações aos artigos de Watson e Crick deveram-se ao reconhecimento histórico ou discussão de fundo, ou seja, base e fundamento para o estudo.

Com base no estudo acima mencionado, em 2010, Bambrilla et al. apresentam pesquisa semelhante ao analisarem o artigo mais citado da Universidade Federal do Rio Grande do Sul - UFRGS, naquele ano, intitulado FTIR thermal analysis on organofunctionilizes silica gel, publicado em 2001 no periódico Jounal of Brazilian Chemical Society. Das vinte e quatro citações recebidas pelo artigo até 2005, vinte e dois dos artigos citantes foram recuperados integralmente nas bases de dados eletrônicas. A análise destes artigos revelou a identificação de apenas uma das categorias das razões de citação apresentadas por Ahmed, et al., inserida na categoria F, ou seja, a de uso de métodos práticos ou teóricos para resolver problemas. 
Ambos os trabalhos representam o alicerce da presente pesquisa que ainda conta com o ferramental teórico apresentado pela vasta bibliografia da área. Autores como Garfield, Case, Higgins, Chen, Le Coadic, Mac Roberts, Solla Price, Lewinson, Moed, van Raan, Werner, Weinstock entre outros, discutem os problemas que envolvem a análise de citação, assim como a importância de se inserir, nestes estudos, uma análise qualitativa, que envolva os motivos que levam um autor a citar outros quando da produção e comunicação de seus trabalhos científicos.

O sistema de classificação de Ahmed et al. (2004) foi especialmente desenvolvido para analisar as razões de citação de um trabalho científico. Este sistema de classificação é composto por sete categorias que se resumem em:

A ) razões históricas, prestação de homenagem aos pioneiros, trabalhos anteriores, mesma concepção do assunto;

B ) descrição de outro trabalho relevante, discussão de detalhes ou partes dos resultados, explicações de como a teoria pode ser usada;

C )uso específico de informação contida no artigo citado;

D )uso de dados para comparação de objetivos;

E )uso de equações teoréticas para quantificar os objetivos;

F )uso de métodos práticos ou teóricos para resolver problemas;

G )crítica ao trabalho citado.

É certo que o ato de citar revela relações, que podem identificar uma proximidade teórica, também conhecida como proximidade paradigmática. $\mathrm{O}$ ato de citar também revela uma identificação do autor citante com um paradigma significando que este autor participa de uma comunidade científica que compartilha de um mesmo referencial teórico. Pode-se então deduzir que citações representam elos de ligação entre autores de uma comunidade científica.

Latour (1986), quando fala da ciência e dos cientistas, chama a atenção para o ciclo de credibilidade. O autor argumenta que vários elementos "nutrem" este ciclo; há aqueles que fazem rodar mais rápido o referido ciclo, como por exemplo, os que recebem muita citação. Desta forma, a busca de créditos é uma rotina para o 
cientista e alimenta a ciência. A cumplicidade que se estabelece entre os cientistas, traduzida pela ajuda concedida entre eles, é o que alguns autores denominam de elos de ligação. Desta forma, dentro desta concepção, cientistas com mais citações tendem a ter mais credibilidade.

As citações bibliográficas são únicas no sentido de que a conexão que elas estabelecem entre documentos são as operações entre cientistas no processo de expor e propagar seus achados na comunidade de pares, que pode ser resumido de certa forma, no processo de geração, validação e comunicação do conhecimento científico.

Para Garfield (1972), citações são links formais e explícitos entre trabalhos (papers) que apresentam pontos particulares em comum.

Rodrigues (1982), define citação como o conjunto de uma ou mais referências bibliográficas que incluídas em uma publicação, evidenciam elos entre indivíduos, instituições e áreas de pesquisa, visto que mostram o relacionamento de uma publicação com outra.

Ahmed et al. (2004) apontam para o conceito de citações como "referências a trabalhos publicados previamente, relevantes para o argumento apresentado pelo autor."

Paul \& Roy (1983) definem análise de citação como "um ramo da bibliometria, onde a unidade de análise é o documento que está sendo citado como referência bibliográfica ou como ota de rodapé num documento citante."

Zimann (1968) ainda complementa que um artigo científico não se sustenta sozinho. Ele precisa inserir-se profundamente na literatura sobre o assunto.

Bormann e Daniel (2008), apresentam o artigo de Gross \& Gross (1927) como o pioneiro no uso da contagem de citações para a avaliação da importância do trabalho científico. A partir daí, constata-se o uso da contagem de citações como ferramenta para a avaliação das políticas nacionais da ciência e seus desenvolvimentos, laboratórios e departamentos de pesquisa, livros, periódicos e dos próprios cientistas. (OPPENHEIM, 1995; 1997; LEWINSON (1998); NARIN (1976); GAR- 
FIELD, 1970; 1972; NICOLAISEN, 2002).

Estes estudos apontam para o uso da análise de citação como medida de impacto do trabalho dos cientistas, dentro da concepção de que um trabalho de grande qualidade atrairia ,ais citações dos pares do que trabalhos de pouca qualidade (VAN RAAN et al, 2003)

Segundo Cole ( 2000) e Van Raan ( 2005), os cientistas interessados na medição do impacto científico apresentam-se divididos em dois campos. O primeiro, defende as análises bibliométricas como apropriadas para a avaliação dos resultados científicos, ou seja, que o número de citações mantem uma correlação direta com a influência e o impacto. Referindo à citação como "procuração", Cronin (2005) apresenta uma lista de estudos sobre essa correlação entre citação e outras formas de avaliação do impacto científico e/ou influência de cientistas tais como prêmios, honras, indicações aos Prêmios Nobel, investimento em pesquisa, ranque acadêmico, etc.

O segundo campo, também interessado nas medidas de impacto, põe em dúvida a contagem de citação como reflexo do impacto da atividade científica. (WOOLGAR, 1991). Autores, defensores dessa linha, tomam como base as afirmações do própro Garfield em 1972, que apontam para o fato da contagem de citação ser uma função de muitas variáveis além do impacto científico. Ou seja, a probabilidade de ser citado depende de variados fatores que nada têm a ver com as convenções já aceitas de publicação acadêmica/científica.

\section{Metodologia}

A pesquisa se deu a partir de duas abordagens centrais: quantitativa e qualitativa. A abordagem quantitativa foi conduzida através de estratégias que incluem a extração, organização e tratamento estatístico das publicações indicadas pelos pesquisadores que constituem a amostra. Assim, partindo dos artigos indicados por estes autores, pretendeu-se analisar indicadores como ano de publicação, peri- 
ódicos em que foram publicados, número de citações recebidas, língua em que os artigos foram escritos e publicados, fator de impacto dos periódicos, entre outros.

A abordagem qualitativa buscou identificar a motivação do ato de citar e teve como referencial teórico metodológico central o estudo de Ahmed et al (2004), que apresenta as três principais formas de se pesquisar as razões de citar; a primeira consiste em analisar os conteúdos dos artigos citantes e julgar as motivações obedecendo critérios pré-estabelecidos, que levaram o autor ou autores a citar. A segunda consiste em entrevistar os autores citantes no intuito de identificar os motivos que os levaram a citar determinados trabalhos. A terceira, também utiliza a entrevista, mas no momento em que o artigo está sendo produzido, com o objetivo de perguntar quem eles estão citando e porque. No presente estudo, utilizou-se a primeira e segunda formas, sendo que esta última, no formato de questionário e não de entrevista.

Para a definição da população do estudo, foi utilizada a Plataforma Lattes para a identificação dos pesquisadores obedecendo aos seguintes filtros: doutores, bolsistas de produtividade do CNPQ. Atuação profissional: grande área: Ciências da Saúde; Área: Medicina; subárea: Clínica Médica; Especialidade: Pneumologia. Líder ou pesquisador cadastrado no diretório dos grupos de pesquisa do CNPq. Foram encontrados 19 pesquisadores, que representaram a população de estudo. Foram retornados 12 questionários.

O questionário aplicado através da ferramenta SurveyMonkey foi elaborado a partir de 22 questões. As três primeiras questões referem-se às autorizações requeridas pelo Comitê de Ética em Pesquisa. A segunda parte refere-se à rotina do pesquisador na academia e a terceira parte, diz respeito à pesquisa e ao processo de produção de trabalhos científicos. Por fim, a quarta parte relaciona-se aos itens que designam qualidade e relevância na pesquisa científica.

A coleta de dados se deu através de duas estratégias principais: coleta de dados na base SCOPUS, com o objetivo de extrair dados dos artigos citantes e coleta de dados, através de questionário, com os objetivos de receber e analisar as respostas. 
A busca na base SCOPUS se deu por autor. Nos resultados obtidos pela busca, foram identificados os dois artigos indicados pelos doze pesquisadores, que responderam os questionários e que integram a amostra, totalizando vinte e quatro artigos. Desses vinte e quatro artigos, foram considerados vinte e dois, pois dois pesquisadores indicaram o mesmo artigo como sendo o de maior qualidade e o de maior relevância. Os vinte e dois artigos foram pesquisados e recuperados com a finalidade de identificar os artigos que citaram cada um deles, ou seja, os artigos citantes. O total de artigos citantes foi de quatro mil setecentos e quarenta e sete.

Com o objetivo de diminuir o universo de artigos citantes, para análise, verificou-se que os anos de 2014, 2015, 2016, 2017 e 2018 apresentaram artigos citantes de quase todos os artigos citados pela amostra. Desta forma, como mostra o Quadro 1, a média de artigos citantes nestes cinco anos foi calculada resultando em quinhentos e setenta e seis artigos citantes. Foram consideradas apenas as publicações classificadas como artigos de pesquisa. Foram recuperados trezentos e setenta e seis artigos, dos quais duzentos e dezenove na íntegra (em acesso aberto). Desta forma, duzentos e dezenove artigos citantes constituíram nossa amostra de artigos para análise. 
Quadro 1- Linha do tempo

\begin{tabular}{|c|c|c|c|c|c|c|c|c|c|c|c|c|c|c|c|c|c|c|c|c|c|c|c|c|c|c|c|}
\hline ARTIGOS & 1.993 & 1.994 & 1.995 & 1.996 & 1.997 & 1.998 & 1.999 & 2.000 & 2.001 & 2.002 & 2.003 & 2.004 & 2.005 & 2.006 & 2.007 & 2.008 & 2.009 & 2.010 & 2.011 & 2.012 & 2.013 & 2.014 & 2.015 & 52.016 & 2.017 & 2.018 & TOTAL \\
\hline ARTIGO 01.1.1 & & & 2 & 26 & 33 & 29 & 45 & 57 & 56 & 64 & 63 & 54 & 53 & 56 & 39 & 52 & 45 & 47 & 40 & 36 & 43 & 30 & 32 & 35 & 26 & 32 & 995 \\
\hline ARTIGO 04.1.1 & & & & & & & & & & & & & & & & & & & & & & & 2 & 10 & 23 & 15 & 50 \\
\hline ARTIGO 05.1 & & & & & & & & & & & & & & & & & & & 4 & 5 & 13 & 7 & 12 & 10 & 9 & 5 & 65 \\
\hline ARTIGO 05.2 & & & & & & & & & & & & & & 24 & 42 & 50 & 39 & 38 & 52 & 45 & 44 & 48 & 59 & 41 & 46 & 45 & 573 \\
\hline ARTIGO 06.1 & & & & & & & & & & & & & & & & & 16 & 31 & 46 & 25 & 31 & 26 & 28 & 18 & 14 & 7 & 242 \\
\hline ARTIGO 06.2 & & & & & & & & & & & & & & & & & & & & & & & & 3 & 2 & & 5 \\
\hline ARTIGO 07.1 & & & & & & & & & & 6 & 4 & 2 & 10 & 5 & 6 & 8 & 9 & 7 & 9 & 11 & 4 & 10 & 2 & 6 & 5 & & 104 \\
\hline ARTIGO 07.2 & & & & & & & & & & & 2 & 5 & 6 & 6 & 9 & 9 & 10 & 7 & 7 & 8 & 10 & 2 & 10 & 8 & 9 & 10 & 118 \\
\hline ARTIGO 09.1 & & & & & & & & & & & & & & & 5 & 10 & 6 & 1 & 6 & 3 & 8 & 4 & 3 & 2 & 8 & 7 & 63 \\
\hline ARTIGO 09.2 & & & & & & & & & & & & & & & & & & 2 & 5 & 7 & 1 & 5 & 4 & 4 & & & 28 \\
\hline ARTIGO 12.1 & & & & & & & & & & 1 & 4 & 3 & 7 & 8 & 7 & 12 & 11 & 11 & 7 & 5 & 5 & 11 & 5 & 7 & 5 & 4 & 113 \\
\hline ARTIGO 12.2 & & & & & & & & & & & & & & & & & & & & & & & 1 & 13 & 5 & 7 & 26 \\
\hline ARTIGO 13.1 & 3 & 2 & 1 & 3 & & & & 2 & 1 & 2 & 2 & 1 & 2 & 4 & 3 & 2 & 1 & 1 & & 2 & & 1 & & & 1 & & 34 \\
\hline ARTIGO 13.2 & & & & & & & & & & 1 & 1 & 2 & 3 & & 1 & 1 & 1 & 1 & 1 & & 1 & & & & 1 & 1 & 15 \\
\hline ARTIGO 14.1 & & & & & & & & & & & & & & & & & & & & & & & 13 & 15 & 16 & 15 & 59 \\
\hline ARTIG0 14.2 & & & & & & & & & & & & & & & & & & & & & & & & 6 & 1 & 10 & 17 \\
\hline ARTIGO 15.1 & & & & & & & & & & & & & & & & & 6 & 3 & 2 & 5 & 1 & 11 & 5 & 7 & 4 & 6 & 50 \\
\hline ARTIGO 15.2 & & & & & & & & & & & 8 & 7 & 9 & 6 & 15 & 15 & 21 & 13 & 16 & 16 & 17 & 14 & 11 & 12 & 13 & 10 & 203 \\
\hline ARTIGO 16.1 & & & & & & & & & & & & & & & & & & & & & 15 & 106 & 124 & 125 & 114 & 99 & 583 \\
\hline ARTIGO 16.2 & & & & & & & & & & & & & & & & & & & & & 5 & 152 & 314 & 318 & 305 & 251 & 1.345 \\
\hline ARTIGO 18.1 & & & & & & & & & & & & & & & & & & & & & 4 & 10 & 8 & 9 & 12 & 10 & 53 \\
\hline ARTIGO 18.2 & & & & & & & & & & & & & & & & & & & & & & 2 & 1 & 2 & 1 & & 6 \\
\hline TOTAL & 3 & 2 & 3 & 29 & 33 & 29 & 45 & 59 & 57 & 74 & 84 & 74 & 90 & 109 & 127 & 159 & 165 & 162 & 195 & 168 & 202 & 439 & 634 & 651 & 620 & 534 & 4.747 \\
\hline & & & & & & & & & & & & & & & & & & & & & & & & & & & \\
\hline
\end{tabular}

Fonte: Elaboração dos autores. 
Para melhor visualizar a metodologia aplicada, apresentamos o mapa conceitual explicativo de todas as etapas.

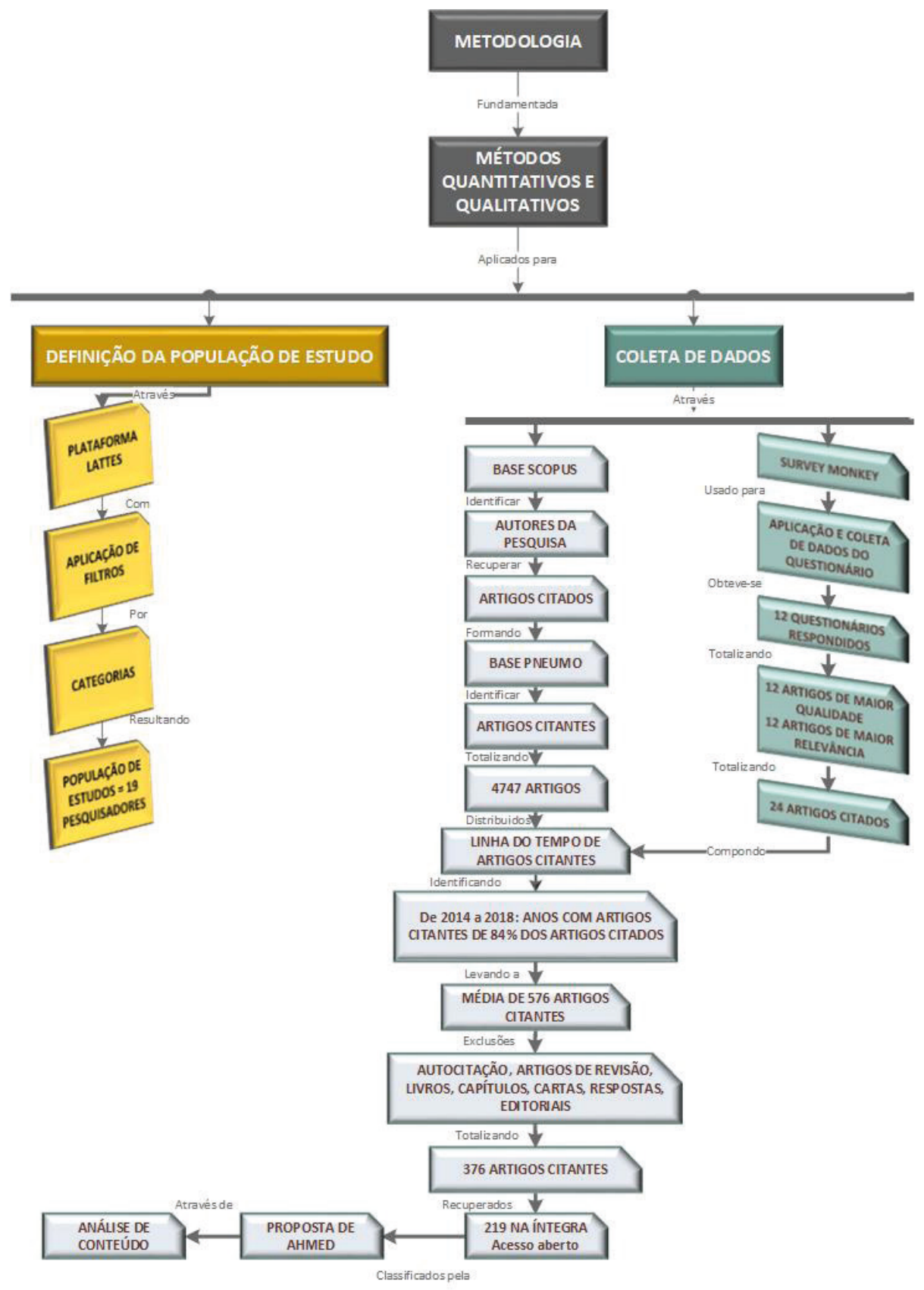

Fonte: Elaborado pelos autores. 


\section{Resultados}

A análise dos resultados se deu através das técnicas de análise documental e análise de conteúdo.A análise de conteúdo dos artigos citantes, por seu grau de subjetividade, foi conduzida pelos autores: doutorando e orientador. Havendo divergência entre as análises, uma terceira pessoa, nesse caso o coorientador o fez, após leitura cuidadosa do conteúdo.

O questionário, constituído por vinte e duas perguntas, teve o tempo estimado necessário para completar a pesquisa de aproximadamente vinte minutos. Dos dezenove pesquisadores que constituíram a população de estudo, obteve-se o retorno de doze questionários, os quais fizeram parte da amostra.

Quanto à primeira parte do questionário, todos os doze respondentes deram seus consentimentos e autorizações exigidos pelo Conselho de Ética em Pesquisa (CEP). Já a segunda parte, perguntas de 4 a 12, referiram-se ao que os autores denominaram de "Pesquisadores e a rotina na academia", sendo estas do tipo assertivas, cujas respostas poderiam variar numa escala de valor.

A análise das respostas evidenciou que não foi possível estabelecer nenhuma correlação entre os índices de citação com o tempo dedicado às atividades acadêmicas objetivo (c). Da mesma forma, os resultados mostraram-se inconclusivos sobre o tipo de atividade acadêmica que influencia a produção de artigos e o número de citações, conforme apresentado nos quadros 2,3 e 4. 
Quadro 2 - Horas aula graduação e pós graduação.

\begin{tabular}{|c|c|c|c|c|c|c|}
\hline \multirow{2}{*}{ PESQUISADOR } & \multirow{2}{*}{\begin{tabular}{|l|} 
PRODUÇÃO \\
DE ARTIGOS
\end{tabular}} & \multirow{2}{*}{\begin{tabular}{|c|} 
№ \\
CITAÇÕES \\
\end{tabular}} & \multicolumn{2}{|c|}{ HORAS AULA GRAD. } & \multicolumn{2}{|c|}{ HORAS AULA POS } \\
\hline & & & MÍNIMO & MÁXIMO & MÍNIMO & MÁXIMO \\
\hline PESQ. 5 & 185 & 10.049 & 0 & 4 & 5 & 8 \\
\hline PESQ. 9 & 154 & 7.147 & 0 & 4 & 5 & 8 \\
\hline PESQ. 16 & 137 & 7.014 & 5 & 8 & 0 & 4 \\
\hline PESQ. 13 & 183 & 5.315 & 0 & 4 & 5 & 8 \\
\hline PESQ. 12 & 273 & 4.408 & 0 & 4 & 5 & 8 \\
\hline PESQ. 15 & 181 & 3.886 & 0 & 4 & 9 & 12 \\
\hline PESQ. 4 & 165 & 3.647 & 0 & 4 & 5 & 8 \\
\hline PESQ. 6 & 87 & 2.732 & 0 & 4 & 0 & 4 \\
\hline PESQ. 7 & 56 & 1.897 & 0 & 4 & 9 & 12 \\
\hline PESQ. 1 & 80 & 1.536 & 5 & 8 & 0 & 4 \\
\hline PESQ. 14 & 92 & 1.247 & 0 & 4 & 5 & 8 \\
\hline PESQ. 18 & 67 & 721 & 0 & 4 & 9 & 12 \\
\hline
\end{tabular}

Fonte: Elaborado pelos autores.

Quadro 3 - Horas orientação graduação e pós graduação.

\begin{tabular}{|c|c|c|c|c|c|c|}
\hline \multirow{2}{*}{ PESQUISADOR } & \multirow{2}{*}{$\begin{array}{l}\text { PRODUÇÃO } \\
\text { DE ARTIGOS }\end{array}$} & \multirow{2}{*}{\begin{tabular}{|c||} 
№ \\
CITAÇÕES
\end{tabular}} & \multicolumn{2}{|c|}{ HORAS ORIENTAÇÃO GD. } & \multicolumn{2}{|c|}{ HORAS ORIENTAÇÃO PÓS } \\
\hline & & & MÍNIMO & MÁXIMO & MíNIMO & MÁXIMO \\
\hline PESQ. 5 & 185 & 10.049 & 0 & 4 & 5 & 8 \\
\hline PESQ. 9 & 154 & 7.147 & 0 & 4 & 5 & 8 \\
\hline PESQ. 16 & 137 & 7.014 & 0 & 4 & 9 & 12 \\
\hline PESQ. 13 & 183 & 5.315 & 0 & 4 & 5 & 8 \\
\hline PESQ. 12 & 273 & 4.408 & 0 & 4 & 5 & 8 \\
\hline PESQ. 15 & 181 & 3.886 & 0 & 4 & 9 & 12 \\
\hline PESQ. 4 & 165 & 3.647 & 0 & 4 & 5 & 8 \\
\hline PESQ. 6 & 87 & 2.732 & 0 & 4 & 0 & 4 \\
\hline PESQ. 7 & 56 & 1.897 & 0 & 4 & 9 & 12 \\
\hline PESQ. 1 & 80 & 1.536 & 0 & 4 & 5 & 8 \\
\hline PESQ. 14 & 92 & 1.247 & 0 & 4 & 5 & 8 \\
\hline PESQ. 18 & 67 & 721 & 0 & 4 & 9 & 12 \\
\hline
\end{tabular}

Fonte: Elaborado pelos autores. 
Quadro 4 - Horas de atividades de extensão e projetos de pesquisa

\begin{tabular}{|c|c|c|c|c|c|c|c|c|c|c|}
\hline \multirow{2}{*}{ PESQUISADOR } & \multirow{2}{*}{\multicolumn{2}{|c|}{$\begin{array}{l}\text { PRODUÇÃO N NQ } \\
\text { DEARTIGOS CITACÖES }\end{array}$}} & \multicolumn{2}{|c|}{ ATIV. EXT.E/OU ASSIST. } & \multicolumn{2}{|c|}{ DESENV. PROJ.PESQUISA } & \multicolumn{2}{|c|}{ ADM. PROI.PESQUISA } & \multicolumn{2}{|c|}{ ESCREVER PROJ. PESQUISS } \\
\hline & & & MINIMO & MÁXIMO & MiNIMO & MÁxIMO & MiNIMO & MÁXIMO & MiNIMO & MÁXIMO \\
\hline PESQ. 5 & 185 & 10.049 & & & 0 & 4 & 0 & 4 & 5 & 8 \\
\hline PESQ, 9 & 154 & 7.147 & 5 & 8 & 0 & 4 & 5 & 8 & 5 & 8 \\
\hline PESQ, 16 & 137 & 7,014 & 9 & 12 & 5 & 8 & 0 & 4 & 0 & 4 \\
\hline PESQ. 13 & 183 & 5.315 & 0 & 4 & 0 & 4 & 0 & 4 & 0 & 4 \\
\hline PESQ, 12 & 273 & 4,408 & 0 & 4 & 21 & 24 & 5 & 8 & 13 & 20 \\
\hline PESQ, 15 & 181 & 3.886 & 5 & 8 & 5 & 8 & 5 & 8 & 13 & 20 \\
\hline PESQ, 4 & 165 & 3.647 & 0 & 4 & 5 & 8 & 0 & 4 & 0 & 4 \\
\hline PESQ, 6 & 87 & 2.732 & 0 & 4 & 5 & 8 & 5 & 8 & 5 & 8 \\
\hline PESQ.7 7 & 56 & 1.897 & 5 & 8 & 9 & 12 & 5 & 8 & 5 & 8 \\
\hline PESQ.1 & 80 & 1.536 & 9 & 12 & 0 & 4 & 5 & 8 & 5 & 8 \\
\hline PESQ, 14 & 92 & 1.247 & 0 & 4 & 5 & 8 & 0 & 4 & 5 & 8 \\
\hline PESQ, 18 & 67 & 721 & 13 & 20 & 5 & 8 & 0 & 4 & 0 & 4 \\
\hline
\end{tabular}

Fonte: Elaborado pelos autores.

A pergunta 13 do questionário refere-se ao fato do pesquisador estar escrevendo ou ter recentemente escrito algum artigo para sua área. 100\% dos respondentes estão ou acabaram recentemente de produzir artigos.

A pergunta de número 14 solicita que os respondentes apresentem que seções, indicadas no questionário, priorizam ao produzir seus papers. Para esta questão o respondente pode indicar mais de uma seção. A metodologia, foi apontada por $61,54 \%$ dos respondentes, enquanto a definição de objetivos por 46,15\%. 38,46\% apontam o resumo e a conclusão. 30,77\% a introdução e 23, 08\% o desenvolvimento. 7, 69\% indicaram as referências. 


\section{Q14 Ao escrever um artigo para um periódico especializado, quais das seções abaixo você prioriza?}

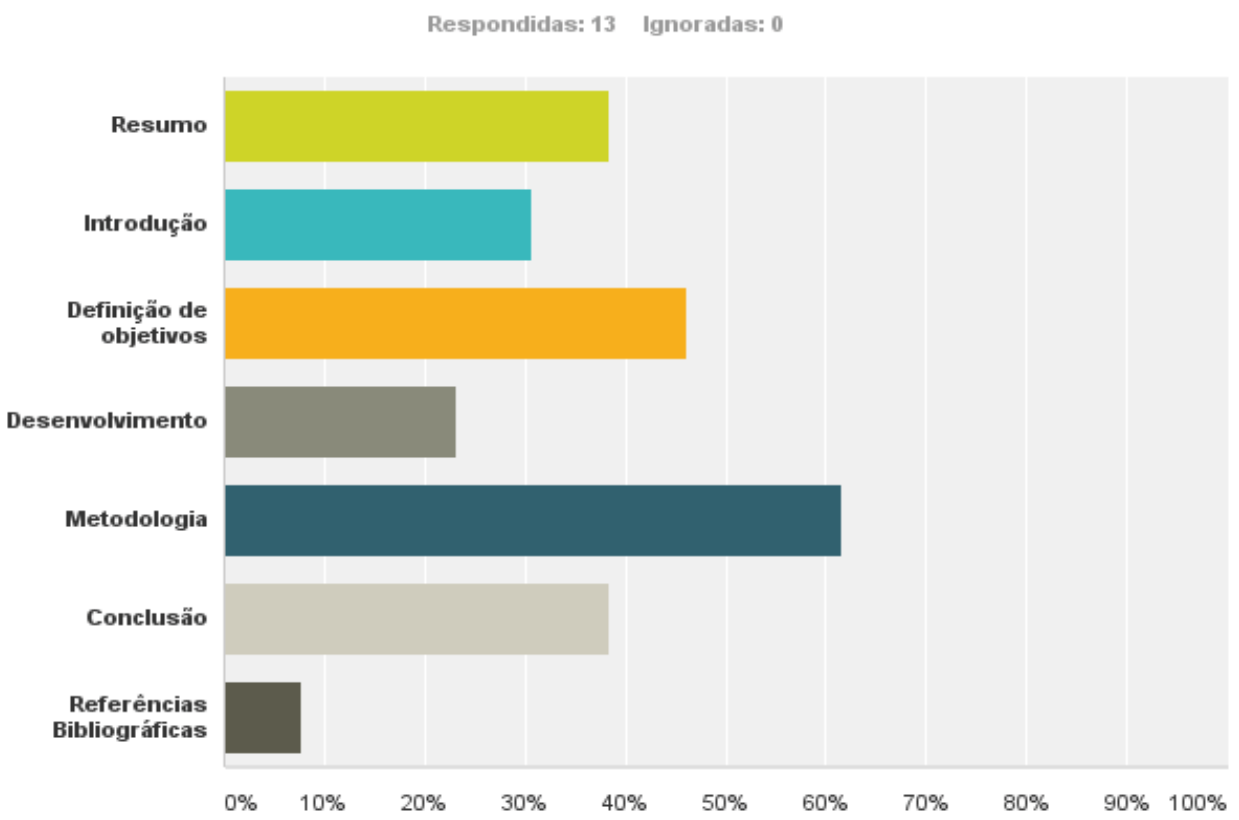

Fonte: Elaborado pelos autores com auxílio da ferramenta SurveyMonkey.

A pergunta 15 refere-se às decisões quanto à submissão de artigos. 92,31\% prefere submeter seus artigos à periódicos internacionais e apenas 7,69\% à periódicos nacionais.

A pergunta 16 refere-se à escolha das referências a serem utilizadas na escrita de um paper. Aqui também os pesquisadores puderam indicar mais de um quesito e as respostas obedecem a uma escala de valor que vai do nunca, passando pelo eventualmente e sempre, até o "não sei dimensionar".

$68,67 \%$ apontam os autores como eventualmente levados em conta, enquanto 25\% apontam que sempre levam em consideração esse quesito. 92,31\% indicam 
que sempre levam em conta o assunto, enquanto $7,69 \%$ indicam o mesmo quesito como eventualmente. A data de publicação é indicada por 33,33\% como sempre levada em consideração, enquanto $58,33 \%$ indicam que eventualmente levam em consideração o mesmo quesito. 23,08\% indicam que eventualmente consideram este quesito. 53,85\% indicam o fator de impacto do periódico como sempre levado em consideração, enquanto $30,77 \%$ o apontam como eventualmente levado em consideração. 15,38\% indicam que sempre levam em consideração o número de citações, enquanto $30,77 \%$ indicam que sempre levam em consideração este quesito. Podemos, desta forma inferir que o assunto, assim como o fator de impacto são itens importantes para a escolha das referências para os pesquisadores da área de Pneumologia, que constituiram nossa amostra.

Q16 Ao escrever um artigo, a escolha das referências que usará leva em conta:

Respondidas: 13 Ignoradas: 0

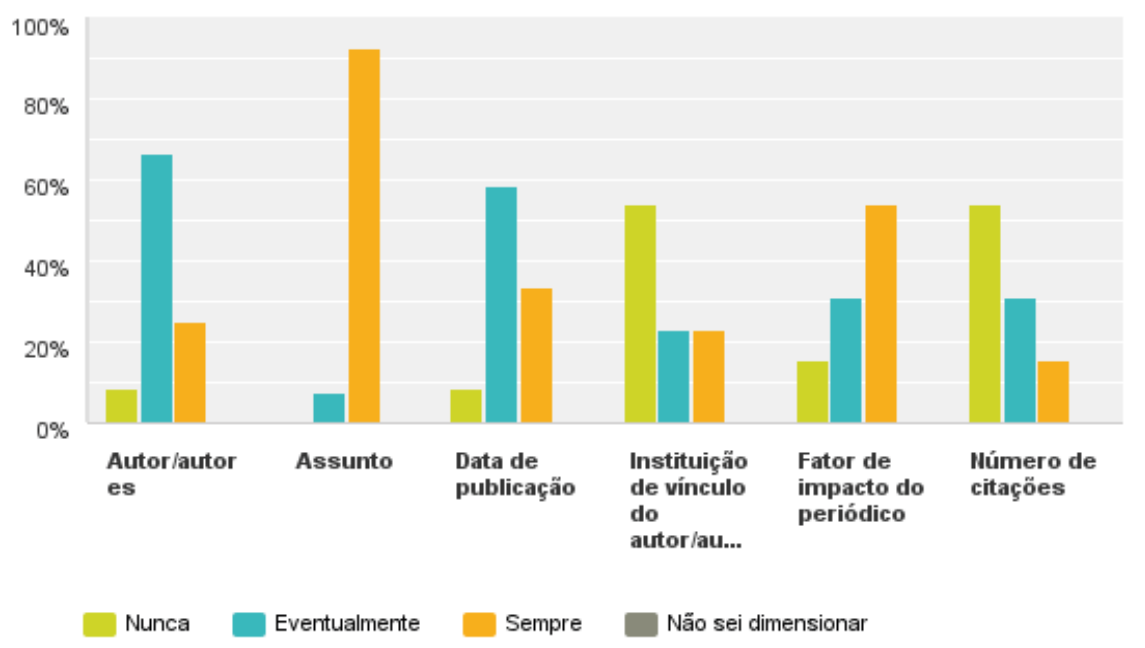

Fonte: Elaborado pelos autores com auxílio da ferramenta SurveyMonkey.

A questão 17 solicita que os respondentes definam o que seja qualidade em um artigo científico. A análise das respostas revela que a metodologia empregada na pesquisa, a definição de objetivos, assim como a apresentação dos resultados e 
conclusões são quesitos definidores de qualidade.

A questão 18, por sua vez, solicita que os respondentes indiquem o que seja relevância em um artigo científico. A contribuição para a área e a aplicabilidade dos resultados foram indicados como fatores decisivos.

A questão 19 solicita aos pesquisadores que indiquem os quesitos que consideram definidores da qualidade de um artigo científico. A análise dos resultados revela que $92,31 \%$ concordam plenamente com o quesito Metodologia como indicador de qualidade. O mesmo percentual é indicado para a análise dos resultados. 69,23\% indicam a conclusão do artigo, enquanto $30,77 \%$ concordam plenamente com a aplicabilidade dos resultados. 46,15\% apenas concordam que o fator de impacto do periódico seja um indicador de qualidade. $30,77 \%$ concordam com o quesito conclusão. 46,15\% concordam com a aplicabilidade dos resultados e 76,92\% acreditam que o número de citações é indicador deste quesito. Aqui, pode-se apontar para uma coerência entre o que os pesquisadores definiram como qualidade e relevância de um artigo científico e suas escolhas para as referências a serem usadas.

No entanto, percebemos um percentual forte que concorda que o número de citações é um ítem importante para as referências/citações. 


\section{Q19 A QUALIDADE de um artigo científico pode ser medida por:}

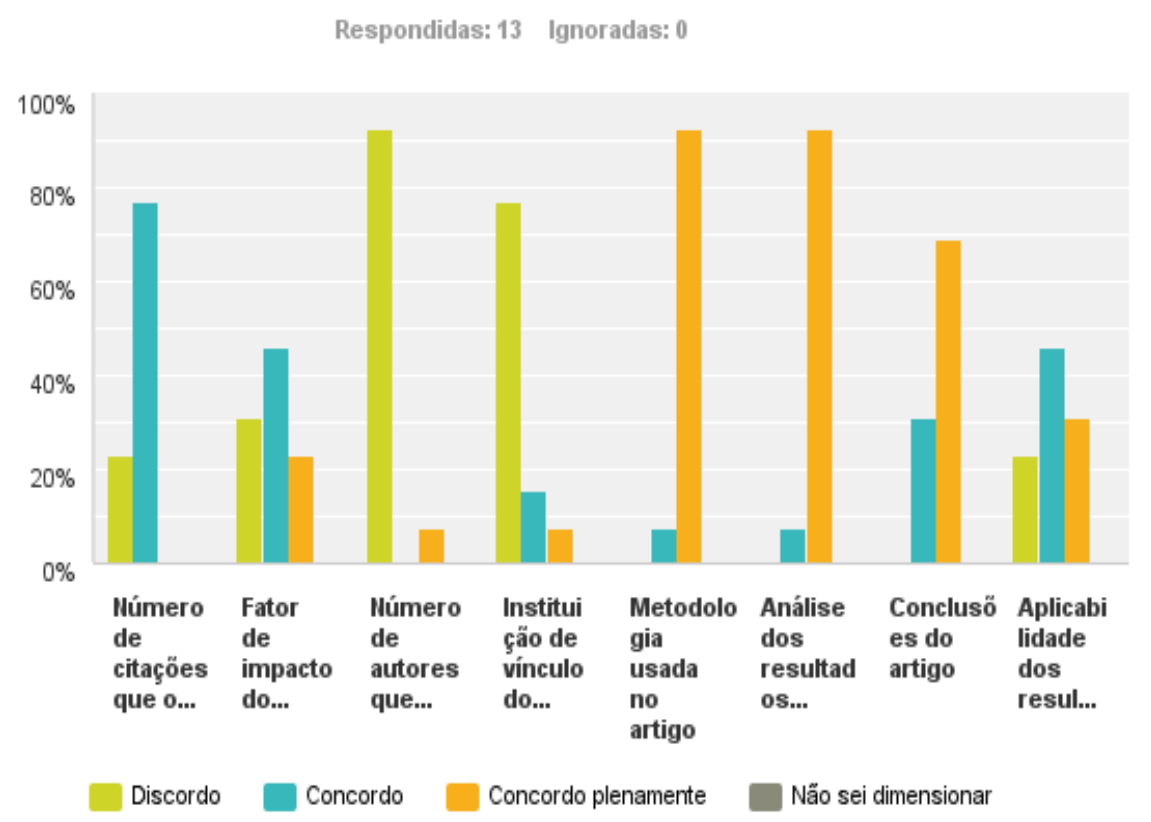

Fonte: Elaborado pelos autores com auxílio da ferramenta SurveyMonkey.

92,31\% discordam que o número de autores do artigo seja indicador de qualidade, enquanto 76,92\% discordam da instituição de vínculo do autor. 30,77\% discordam do fator de impacto do periódico, 23,08\% do número de citações e o mesmo percentual para a aplicabilidade dos resultados.

A questão 20 refere-se à relevância do artigo científico. Os mesmos quesitos da questão 19 foram oferecidos aos respondentes com a mesma escala de valor. Os respondentes concordam plenamente que os quesitos metodologia e análise dos resultados definem a relevância do artigo científico. As conclusões do artigo também são apresentadas como quesito importante. Os respondentes também discordam com os quesitos número de autores e instituição de vínculo dos mesmos como indicadores de relevância do artigo. $66,67 \%$ concordam que o número de citações seja indicador de relevância. 58,33\% concordam que a metodologia seja indicadora de relevância. 


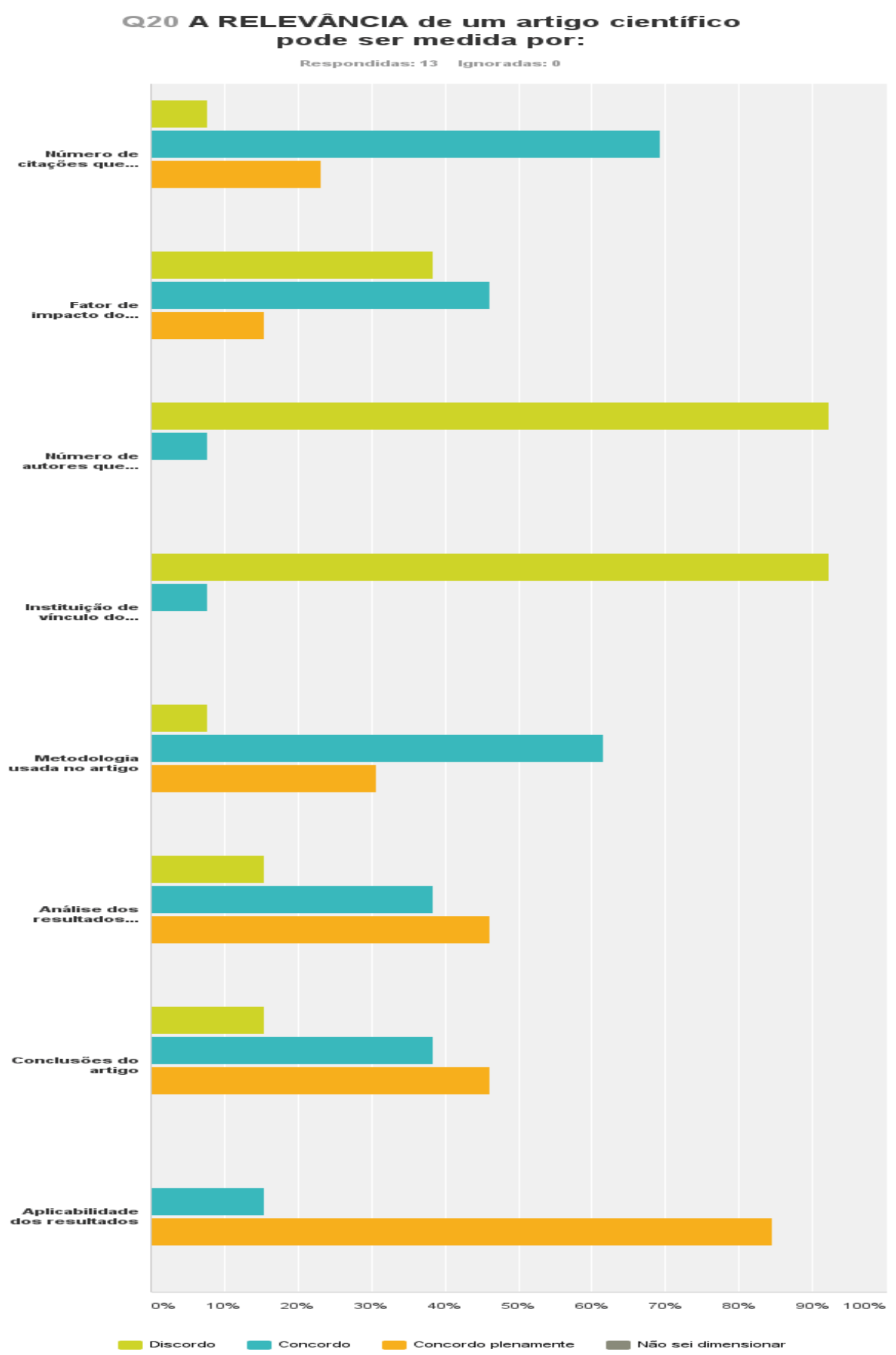


As questões 20 e 21 solicitam aos respondentes que indiquem um artigo de sua autoria que consideram de maior qualidade e um artigo que consideram de maior relevância. A partir destas indicações, foram identificados quatro mil setecentos e quarenta e sete artigos citantes que, após análise através do tempo e a aplicação de exclusões e exceções totalizaram, conforme descrito na metodologia, duzentos e dezenove artigos citantes para análise.

A partir das indicações dos pesquisadores dos artigos considerados por eles como de maior qualidade e relevância, foi verificado que o artigo mais citado dentre todos os indicados foi artigo 16.2, do quadro 5, publicado em 2013 com mil trezentas e quarenta e cinco citações, conforme a base SCOPUS. Esse mesmo artigo, indicado como de maior relevância, é o artigo mais citado do pesquisador. O artigo 04.1.1, do mesmo quadro publicado em 2015, foi indicado como o de maior qualidade e o de maior relevância pelo pesquisador, com cinquenta citações. $\mathrm{O}$ artigo mais citado do pesquisador correspondente obteve quatrocentas e quatro citações. $\mathrm{O}$ artigo 01.1.1, publicado em 1995, com novecentos e noventa e cinco citações foi indicado como o de maior qualidade e o de maior relevância e corresponde ao artigo mais citado do pesquisador. $\mathrm{O}$ artigo 06.1, indicado como de maior qualidade, com duzentas e quarenta e duas citações, também é o artigo mais citado. 
Quadro 5 - Artigos indicados $\mathrm{x}$ artigos mais citados

\begin{tabular}{|c|c|c|c|c|}
\hline Pesquisador & $\begin{array}{l}\text { Qualidade } a \text {. } \\
\text { Relevância }\end{array}$ & $\begin{array}{l}\text { Artigo } \\
\text { Indicado }\end{array}$ & $\begin{array}{l}\text { Número de } \\
\text { citaçóes }\end{array}$ & $\begin{array}{l}\text { NF de cit acóbs do } \\
\text { artigo mais citado }\end{array}$ \\
\hline Pesquitodor 1 & $\begin{array}{l}\text { QLUALIDADE } \\
\text { PELENÁNCIA }\end{array}$ & $\begin{array}{l}\text { Artigo P1 } 1 \\
\text { Artigo P1 } 1\end{array}$ & 995 & 995 \\
\hline Pequilador 2 & \multicolumn{4}{|c|}{ NAO APRESENTOU ARTIGOS } \\
\hline Pesquitadoir 3 & \multicolumn{4}{|c|}{ NÁO APF ESENTOU AFTIGOS } \\
\hline Pesquirador 4 & $\begin{array}{l}\text { RLALIDADE } \\
\text { RELENÁNCIA }\end{array}$ & $\begin{array}{l}\text { Artigo PA : } 1 \\
\text { Artigo P4 : } 1\end{array}$ & so & 404 \\
\hline Pequulador 5 & $\begin{array}{l}\text { RLIALIDADE } \\
\text { RELENANCIA }\end{array}$ & $\begin{array}{l}\text { Artigo PS : } 1 \\
\text { Artigo PS } 2 \\
\end{array}$ & $\frac{55}{573}$ & 1.325 \\
\hline Perquitador 6 & $\begin{array}{l}\text { RLALIDADE } \\
\text { RELENANCIA } \\
\end{array}$ & $\begin{array}{l}\text { Artigo PG } 1 \\
\text { Artigo PG } 2 \\
\end{array}$ & $\frac{242}{5}$ & 242 \\
\hline Pesquindor 7 & $\begin{array}{l}\text { RLUALIDADE } \\
\text { FELENÁNCLA }\end{array}$ & $\begin{array}{l}\text { Artigo PT: } 1 \\
- \text { Artigo PT }: 2 \\
\end{array}$ & 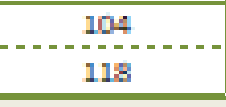 & 422 \\
\hline Pesquirador $\mathrm{s}$ & \multicolumn{4}{|c|}{ NALO APR ESENTOU ARTIGOS } \\
\hline Perquindor 9 & $\begin{array}{l}\text { RLUALIDADE } \\
\text { PELENÁNCIA }\end{array}$ & $\begin{array}{l}\text { Artigo Pg } 1 \\
-1 \\
\text { Artigo Pg }-2\end{array}$ & $=\frac{63}{23}$ & 2.650 \\
\hline Pequiledor 10 & \multicolumn{4}{|c|}{ NADO APR ESENTOU ARTISOS } \\
\hline Pequilador 11 & \multicolumn{4}{|c|}{ NAO APF ESENTOU AFTIGOS } \\
\hline Perquitador 12 & $\begin{array}{l}\text { RLALIDADE } \\
\text { FELENÁNCIA }\end{array}$ & $\begin{array}{l}\text { Artigo P12 : } 1 \\
- \text { Artigo P12 } 2\end{array}$ & $\frac{113}{25}$ & 113 \\
\hline Pequilador 13 & $\begin{array}{l}\text { QLALIDADE } \\
\text { RELENANICIA } \\
\text { RELA }\end{array}$ & $\begin{array}{l}\text { Artigo P13 } 1 \\
\text { Artigo P13 } 2\end{array}$ & $\begin{array}{l}34 \\
15\end{array}$ & 2.550 \\
\hline Pequilador 14 & $\begin{array}{l}\text { QLALIDADE } \\
\text { FELENANACLA }\end{array}$ & $\begin{array}{l}\text { Artigo P14 } 1 \\
\text { Artigo P14 } 2\end{array}$ & $\begin{array}{l}39 \\
17 \\
\end{array}$ & 150 \\
\hline Perquitador is & $\begin{array}{l}\text { QLUALIDADE } \\
\text { PELENÁNCIA } \\
\end{array}$ & $\begin{array}{l}\text { Artigo P1S } 1 \\
\text { Artino P1S } 2 \\
\end{array}$ & $\begin{array}{c}50 \\
200 \\
\end{array}$ & 321 \\
\hline Porquitador 15 & $\begin{array}{l}\text { RLUALIDADE } \\
\text { PELENÁNCLA } \\
\end{array}$ & 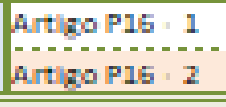 & $\begin{array}{c}\operatorname{se3} \\
1345 \\
\end{array}$ & 1345 \\
\hline Pequindor 17 & & NALOAPF & ENTOL ARTIGOS & \\
\hline Pequilador $1 \mathrm{~s}$ & $\begin{array}{l}\text { PLIALIDADE } \\
\text { RELENÁNCLA }\end{array}$ & $\begin{array}{l}\text { Artigo P1S } 1 \\
\text { Artigo P1s - } 2\end{array}$ & $\begin{array}{c}53 \\
-1\end{array}$ & 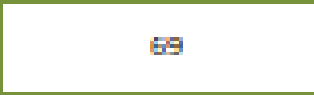 \\
\hline Pequitador 19 & & NADO APF & ENTOL ARTIGOS & \\
\hline
\end{tabular}

Fonte: Elaborado pelos autores 
Quanto a motivação para citação, após análise dos duzentos e dezenove artigos citantes, foram encontrados artigos que referem-se às categoria $\mathrm{A}, \mathrm{B}, \mathrm{C}, \mathrm{D}, \mathrm{F}$ e G. Cento e vinte e seis artigos encontram-se na categoria A, que refere-se a razões históricas, prestação de homenagem aos pioneiros, trabalhos anteriores, mesma concepção do assunto.

A análise evidencia que os pesquisadores da área de Pneumologia citam trabalhos anteriores sobre o mesmo assunto, para servir de base para suas argumentações e desenvolvimento da pesquisa. 57,6\% das citações estão na categoria A de Ahmed et al. (2004).

$21,5 \%$ do total de artigos analisados classificam-se na categoria B que referes-e a descrição e outro trabalho relevante, quando, por exemplo, o artigo oferece informação relevante ou faz afirmação com a qual o autor citante concorda ou quando o conteúdo do artigo é discutido comalgum detalhe, indo além da simples menção.

Os resultados também indicam pela não relação entre qualidade e relevância e artigos mais citados, uma tendência na direção da teoria construtivista, que aponta para o fato da contagem de citação ser uma função de muitas variáveis além do impacto científico. Ou seja, a probabilidade de ser citado depende de variados fatores que nada tem a ver com as questões relacionadas à qualidade e/ou relevância dos artigos.

A presente pesquisa pretendeu não apenas revelar as motivações para o ato de citar, mas contribuir para o uso mais adequado dessa variável como uma das ferramentas de avaliação da pesquisa na área de Pneumologia. 


\begin{tabular}{|c||c||c|}
\hline CATEGORIA & QTD. & $\%$ \\
\hline A & 126 & $57,6 \%$ \\
\hline B & 47 & $21,5 \%$ \\
\hline D & 26 & $11,8 \%$ \\
\hline E & 8 & $3,5 \%$ \\
\hline F & 0 & $0,0 \%$ \\
\hline G & 11 & $4,9 \%$ \\
\hline \hline TOTAL & 219 & $0,7 \%$ \\
\hline
\end{tabular}

\section{LEGENDA}

Categoria A: razões históricas, prestação de homenagem aos pioneiros, trabalhos anteriores, mesma concepção do assunto;

Categoria B: descrição de outro trabalho relevante, discussão de detalhes ou partes dos resultados, explicações de como a teoria pode ser usada;

Categoria C: uso específico de informação contida no artigo citado;

Categoria D: uso de dados para comparação de objetivos;

Categoria E: uso de equações teoréticas para quantificar os objetivos;

Categoria F: uso de métodos práticos ou teóricos para resolver problemas;

Categoria G: crítica ao trabalho citado.

Desta forma, no sentido de promover uma melhor compreensão acerca das categorias de citação propostas por Ahmed et al. (2004), pode-se entender a categoria A como, por exemplo, quando o autor do artigo citado foi a primeira pessoa a trabalhar na área ou quando há citação por aferição de crédito ao artigo citado, 
assim como a leitura de base ou sustentação para o artigo citante. A categoria B, relaciona-se ao fato do artigo citado produzir informação relevante ou quando o artigo citado revela uma afirmação com o qual o autor do artigo citante concorda. A categoria $\mathrm{C}$ quando o autor citado faz uso específico da informação ou dado contido no artigo citado. Já a categoria D, por sua vez, refere-se ao fato do autor citante fazer uso do artigo citado para obter informação que foi utilizada para comparação. A categoria E poderia ser exemplificada através do fato do artigo citante aplicar diretamente a equação teorética citada para fins de cálculo. A categoria $\mathrm{F}$ poderia ser entendida quando o autor citante faz uso de técnica prática ou teórica fornecida pelo artigo citado. A categoria G, quando o autor citado sentiu que era necessário afirmar que determinada teoria ou método não era aplicável, ou não era o melhor para o propósito da pesuisa. O autor citante critica o artigo citado.

\section{Considerações finais}

Estudos de avaliação bibliométrica são baseados na premissa de que o uso da literatura profissional de uma área e sua respectiva citação em publicações refletem o reconhecimento de outro trabalho. Cientistas preenchem este requisito de documentação científica acreditando que o crédito a outro estudo é fornecido se o mesmo for merecedor. Desta forma, cientistas utilizam partes de um texto em suas publicações quando entendem terem sido as mesmas influenciadas pelo texto citante. Alguns estudos acerca do uso das citações em publicações científicas como em Cronin ( 1992) revelam que há uma crença pela sociedade de que cientistas frequentemente falham ao citarem trabalhos pertinentes e que os autores tendem a citar aqueles cujas ideias confirmam as suas próprias. O comportamento dos cientistas ao citarem outros trabalhos também incluem estratégias manipuladoras de citação que refletem um esforço para incluir em seus trabalhos citações que chamem a atenção de editores, revisores ou pares. São duas as teorias relativas ao comportamento de citar; a teoria normativa e a social construtivista. Na teoria normativa as razões 
pelas quais cientistas citam outros cientistas referem-se diretamente à relevância do trabalho citado, no sentido de reconhecimento de um débito intelectual. Já a teoria social construtivista contradiz as hipóteses acima. Nessa visão, as citações refletem um processo psicológico, não isento de viés pessoal ou pressão social. Diferentes motivações para o to de citar são esperadas dependendo do ambiente intelectual ou prático. Alguns autores como Gilbert (1977), percebem as citações como persuasão onde cientistas preferem citar documentos que sejam solidários ao que escrevem, preferencialmente pelos experts da área.

Os resultados da presente pesquisa não revelam relação direta entre artigos que os autores indicam como os de maior qualidade e os de maior relevância com os artigos mais citados, reforçando a teoria construtivista de que o ato de citar é um processo psicológico movido por diferentes razões. Torna-se claro, através dos resultados, que o conceito de qualidade do trabalho científico na área de Pneumologia refere-se às questões relacionadas à compatibilidade da metodologia aplicada aos objetivos do trabalho, assim como os resultados alcançados. No entanto, o número de citações não fica ausente desta avaliação e é indicado como importante. Já a relevância do trabalho científico também aponta para o método, assim como para a aplicabilidade dos resultados.

Em toda pesquisa científica, o cientista pesquisador deve saber não apenas o que deve ser medido, mas também com o que deve ser medido, ou seja: as características do instrumento de medição. Segundo Garfield (1979) o instrumento bibliométrico pode ser utilizado para dois objetivos principais: A avaliação da performance da pesquisa e para o estudo da ciência como um sistema gerador de conhecimento e comunicação e sua interação com a tecnologia. Desta forma, os resultados da pesquisa indicam que o número de citações de um documento é uma variável a se considerar na avaliação do trabalho científico, mas que, por si só, não define a qualidade e relevância do mesmo. 


\section{Referências:}

AHMED, T. et al. Highly cited old papers and the reasons why they continue to be cited. Part II: the 1953 Watson and Crick article on the structure of DNA. Scientometrics, Amsterdam, v. 61, n. 2, p.147-156, 2004.

BORMANN, L.; DANIL, L.H.D. Selection of research fellowship recipients by commitee peer review: analysis of reliability, fairness and predictive validity of board of turstees decisions. Scientometrics, v.63, p. 3-72, 2008.

BRAMBILLA, S. D.; VANZ, S. A.; STUMPF, I. R. Mapeamento de um artigo produzido na UFRGS: razões das citações recebidas. Disponível em: http://www.periodicos.ufsc.br/index.php/eb/article/viewFile/359/423. Acesso em: 8 ago. 2010.

COLE, JR. A short history of the use of citations as a measure of the impact of scientific and scholarly work. In: CRONIN, B; ATKINS, H. B. The web of knowledge: a festschrift in honor of Eugene Garfield. New Jersey: Information Today, 2000.

CRONIN, B. The citation process: the role and significance of citations in scientific communication. Oxford: Taylor Graham, 1984.

HOOD, W. W.; WILSON, C. S. The literature of bibliometrics, scientometrics, and infometrics. Scientometrics, v. 52, p. 291-314, 2001.

GARFIELD, E. Citation indexing for studying Science. Nature, v. 227, p. 669-71, 1970.

. Citation analysis as a tool in journal evaluation: journals can be ranked by frequency and impact of citations for science policy studies. Science, v. 178, p. 471-9, 1972.

GILBERT, G. N. Referencing as persuasion. Social Studies of Science, v.7, p113-22, 1977.

LATOUR, Bruno; WOOLGAR, Steve. Laboratory life: the social construction os scientific facts. Oxford: Princeton University Press, 1979.

LETA, Jacqueline. As citações na ciência brasileira: concepções da comunidade científica versus tendências e desempenho nas bases de dados. Projeto submetido ao CNPq, edital MCT/CNPq n. 014/2010-Universal, 2010.

LEWISON, G. The effect of funding on outputs of biomedical research. Scientometrics, v. 41, p.1727. 1998.

MACROBERTS, M. H.; MACROBERTS, B.R. Problems of citation analyses: a critical review. Journal of the American Society for Information Science, v. 40, p. 432-9. 1989.

MOED, H. F. The impact factors debate: ISI's uses and limitations. Nature, n. 415, p. 731-732, 2002.

MOHAM, P; ROY, R. Citation analysis: a new tool for the modern librarian. IASLIC Bulletin v. 25, n. 3, p. 39-49, 1994.

NICOLAISEN, J. The J-shape distribution of citedness. Journal of Documentation, v.58, p. 383-95, 2002

NARIN, F. Evaluative bibliometrics: the use of publication and citation analysis in the evaluation of scientific activity. Ontario: Computer Horizons, 1976.

OKUBO, Y. Bibliometric indicators and analysis of research systems: methods and examples. Paris: OCDE/GD, 1997. 
OPPENHEIM, C. The correlation between citation counts and the 1992 research assessment ratings for British libraries and information science university departments. Journal of Documentation, v. 51, n. 1, p. 18-27, 1995.

RODRIGUES, Maria da Paz Luis. Citações nas dissertações de mestrado em Ciência da Informação. Ciência da Informação. V.11, n.1, p.35-61, 1982.

TIJSSEN, R,J,W.; VAN LEEUWEN, T. N.; VAN RAAN, A.F.J. Mapping the scientific performance of german medical research; an international comparative bibliometric study. Schattauer: Stuttgart, 2002.

VAN RAAN, A. F. J. et al. Bibliometric analysis of psychotherapy research performance assessment and position in the journal landscape. Scientometrics, v. 13, p. 511-28, 2003.

For your citation only? Hot topics in bibliometric analysis. England: Measurement Interdisciplinary Research and Prespectives, v. 3, p. 50-62, 2005.

WARNER, J. A. A critical review of the application of citation studies to research assessment exercises. Journal of Information Science, v. 26, n. 6, p. 453-460, 2000.

WATSON, J. D.; CRICK, F. H. C. Molecular structure of nucleic acids: a structure for Deoxyribose nucleid acid. Nature, v. 171, p. 737-8

WOOLGAR, S. Beyond the citation debate: towards a sociology of measurement technologies and their use in science policy. Science Public Policy, v.18, p.319-26, 1991.

ZIMANN, J. Conhecimento público e dimensão social da ciência. São Paulo: EDUSP, 1968. 